Canadian Oncology

Nursing Journal

Revue canadienne

de soins infirmiers

en oncologie

Volume 27, Issue 4 • Fall 2017

elSSN: 2368-8076 


\title{
Systematic screening of distress: Portraits and cross-examination of the various stakeholders' perceptions, clinical perspectives, and research- Part 2
}

\author{
by Nicole Tremblay, Odette Roy, and Aurélie Lecoc, in partnership with Caroline Provencher, Louise Compagna, Francine \\ Grondin, Karine Le Breton, and Jocelyne Doucet
}

\section{INTRODUCTION}

I

n our study's first phase, which dealt with the screening of distress in breast or hematological cancer patients and was the topic of Part 1 of this article (Tremblay et al., 2017), we painted a portrait of the distress of these two groups of participants. We highlighted that although nearly 34\% (33.9\%) of our sample ( $\mathrm{N}=532$ participants) reached a clinical score of 5 or more on the Distress Thermometer (DT), only a low percentage $(22.7 \%)$ wished to receive help with problems expressed in the screening process. This somewhat low percentage dropped further at Time 2 (14.7\%). This DT score justified a more targeted assessment of the distress. This was also the case for the following results: slightly over 1 in 4 patients (26.6\%) displayed an Edmonton Symptom Assessment System (ESAS) score superior or equal to 5 for anxiety at Time 1, and $18.4 \%$ did at Time 2. For depression, 9.4\% of patients scored higher or equal to 5 at Time 1, and $9.5 \%$ did at Time 2. These situations should prompt further exploration, generally by a psycho-oncologist.

It was also noted that study participants were more likely to accept referrals when offered during discussion of patients' Distress Screening Tool (DST) results (40\% of cases at Time 1 and $33 \%$ at Time 2). This is clearly significant for clinical

\section{ABOUT THE AUTHORS}

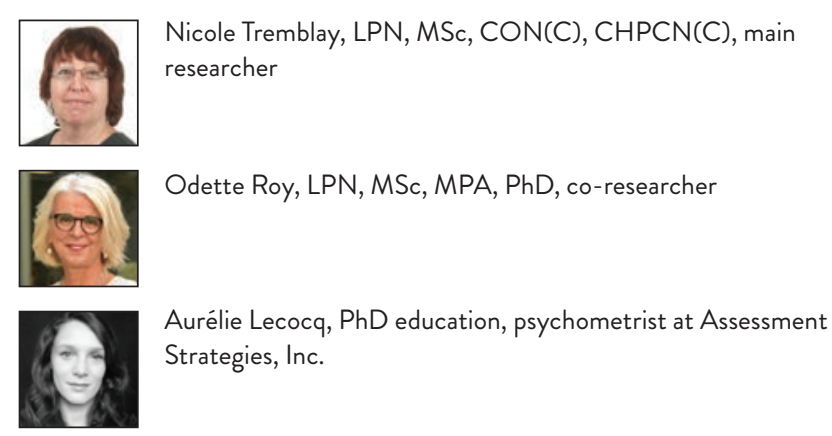

In partnership with

Caroline Provencher, LPN, MSc

Louise Compagna, LPN, BSc

Francine Grondin, LPN, BSc

Karine Le Breton, LPN, MSc, CON(C)

Jocelyne Doucet, LPN, BSc, research assistant

Cécile Mathurin, LPN, MSc, research assistant

DOI: $10.5737 / 23688076274328337$ nursing practice, as other moments in the care trajectory (such as the treatment period and admission to the transplant unit) are also more favourable to acceptance of the help offered.

Another significant finding: At Time 2, the proportion of patients with a score greater than or equal to 5 on the DT dropped to $28.1 \%$. However, this reduction occurred whether or not the referral had been accepted or refused, except in the case of social issues where levels of distress were significantly lowered when the patient accepted. These results may indicate both the cancer clientele's capacity for resiliency and the benefits of support and education, mainly by nurses, that go greatly undocumented (De Marinis, et al., 2010; Tremblay et al., 2017).

The various phenomena described in Phase 1 of this study justify our interest in better understanding the various relational issues behind these results, particularly patients' and nurses' perceptions of systematic screening for distress, to explore its content and its points of convergence and divergence. The rest of this article will therefore present the findings of Phase 2 of this study regarding these perceptions.

\section{METHODS}

\section{Design}

As described in Part 1, an exploratory sequential mixed research design was developed and used to capture complex realities, such as nurse-patient interactions around topics that are potentially emotionally charged in a new and unpredictable context (Foss \& Ellefsen, 2002).

\section{Study objectives}

This study had five distinct goals. This article will present the results of Objectives 3 and 5, and part of 4. The study objectives were set according to the populations under study. The first three were identical for the two cancer clienteles. The fourth objective specifically targets the hematological cancer and transplant population, while the fifth focuses on breast cancer patients.

\section{Hematological and breast cancer populations \\ Objectives:}

1. To collect information on the psychological distress experienced by the targeted clientele at specific moments of the care trajectory (Phase 1);

2. To collect information on the process of implementing systematic screening for distress in the various sectors affected by the screening (Phases 1-3); 
3. To better know nurses' perceptions of this systematic screening for distress in the context of hematological cancers, hematopoietic cell transplants and breast cancers (Phase 2).

The fourth objective was described as follows:

4. To better know patients' perspective on this systematic screening for distress in the context of hematological cancers and hematopoietic cell transplants (Phases 2 and 3).

The fifth objective was:

5. To better understand female breast cancer patients' perceptions of the screening for distress (Phase 2).

\section{Ethical considerations}

We reiterate the ethical considerations mentioned in Part 1 of this article. This study obtained an ethical certificate in early 2013 from the learning establishment in which it was conducted. It should be mentioned that since systematic screening for distress is considered a standard oncological intervention, no consent other than verbal agreement from the clientele at the time of screening was required. However, written consent was obtained from participants for all other phases of the study.

\section{Data collection and analysis}

The instruments used in this phase of the study-a questionnaire of nurses' perceptions (QNP) and a questionnaire of patients' perceptions (QPP)—were developed from study findings (Asselin, 2012; Blais, 2012) on systematic screening for distress presented in November 2012 to the CHU de Québec during an Oncology Scientific Day. Moreover, two English-language questionnaires developed by Alberta Health Services (AHS, 2012, A and B) were used to gather both the patients' perceptions of the quality of care and nurses' perspectives on the screening for distress instrument, as part of the IPODE Project for the implementation of screening for distress. ${ }^{1}$ These questionnaires were also improved upon following the findings of a focus group of nurses in the implementation process of screening for distress in our healthcare centre. The AHS's tool was translated into French and adapted with permission.

The QPP is a mixed questionnaire (both quantitative and qualitative) of 15 questions with sub-questions. It addresses various aspects connected to screening for distress, particularly the ease of completing the DST, the utility of the DST, if the screening process is emotionally troubling, the help requested and the help received.

The QNP has 15 questions with sub-questions. It is also a mixed questionnaire. It addresses the meaning and importance nurses ascribe to the screening. It also measures nurses' perception of the importance patients ascribe to this screening, and nurses' comfort with various aspects of their screening practice.

1. EDOPI-IPODE. An online educational screening for distress program that was designed to train staff (namely, nurses). Global Cancer Experience, (2012) CPAC. Screening for Distress, the 6th Vital Sign: A Guide to Implementing Best Practices in Person-Centred Care. www. cancerview.ca
Parametrical tests were performed when the sample size so allowed. The qualitative analysis was carried out according to a simple categorization by the two main researchers (NT and OR), independently at first. They let the themes emerge from several readings of the handwritten answers. A first categorization was made for each question. The researchers then distilled the themes and compared the categories obtained. For each question, nearly perfect consensus was reached upon first comparison, and discussion led to consensus for the remaining categories.

\section{RESULTS}

\section{Sample characteristics}

Patient participants

Our convenience sample was made up of 122 cancer patients, 80 of whom had breast cancer and 42 hematological cancer. Recruitment took place throughout 2014. To be eligible for the study, participants had to have completed the DST process at least once. Those who had not were excluded from the study. This questionnaire did not collect sociodemographic data. However, the same groups of participants were solicited for the study's second phase as for its first, when age and diagnosis were obtained. It is, therefore, reasonable to think that this information can be transposed to Phase 2 .

\section{Nurse participants}

Our convenience sample consisted of 45 nurses, a majority of whom (64.4\%) work with hematological cancer patients. A smaller proportion worked mainly with breast cancer patients (1.3\%) and $20 \%$ with various oncology clienteles (patients with various cancers in chemotherapy or radiotherapy). This distribution of nurse participants reflects the distribution in our establishment's oncology department. More of these nurses work with a hematological cancer clientele given they are affiliated with a hospital unit that covers three work shifts, as compared to nurses working in walk-in oncology clinics with patients who have all types of cancer or to nurses working just with breast cancer patients.

\section{Patient perceptions of the questionnaire \\ Presentation}

Of the 122 participating patients, a vast majority (97.5\%) was presented with the screening instruments (three breast cancer patients reported that they had not seen the tool).

\section{Ease of completion}

The majority of study participants (77\%) found the screening tool "easy" to use. Some participants $(17.2 \%)$ found the instrument "somewhat easy" to complete, or "difficult" (3.3\%). Information was missing for three people. Although more hematological cancer patients $(7.5 \%)$ than breast cancer patients $(1.3 \%)$ found the tool difficult to use, this difference is not significant.

\section{Purpose}

Two main themes emerged from participants' answers to the question "In your opinion, what is this questionnaire used for?" (An $\mathrm{H}$ preceding the participant number indicates a hematological cancer patient, while an S is used for participants with breast cancer.) 
The first theme grouped patients verbatim on evaluation or screening for distress, stress, anxiety, needs or fears. The following illustrates this theme:

S39: It is used to screen for psychological distress stemming

from the experience of breast cancer (in my case).

The second theme grouped patients verbatim on help. Participants answered that the DST is intended to help them or professionals. The instrument is perceived as being used to see if patients need help or to identify necessary actions to help them or redirect them to appropriate resources. Two verbatims illustrate this theme:

S2: To measure the degree and type of help patients need.

H14: To validate my fears and measure my level of anxiety so as to orient me toward necessary resources, if needed.

\section{Perceived utility and explanations}

To the question "Did you find it useful to complete the screening for distress questionnaire?" a vast majority of participants $(81.1 \%)$ answered yes. Four people checked both yes and no. After reading their comments when asked to specify the reasons for this double choice, we considered them a yes. Figure 1 presents the answers to this question.

The major theme that emerged from our analysis of the reasons behind an affirmative answer was the introspective character of the screening tool. To our knowledge, no study has yet shed light on this element. According to our participants, completing the tool was an opportunity to take stock of their emotions or experiences, as the following verbatims illustrate:

S2: "I was feeling strong. When I read through the questions though, I felt weaker than I thought. That surprised me."

S69: "Yes. This was the moment when I realized just how much anger I was feeling about this diagnosis. I felt deepseated injustice."

S76: "It allowed me to clarify my stress and see what my needs were."

Participants also perceived the tool to be useful because it was a form of sharing or communication around their experience and emotions.

S38: "Yes, I was able to express some anxiety that, although minimal, I hadn't shared with my family. It was a relief."

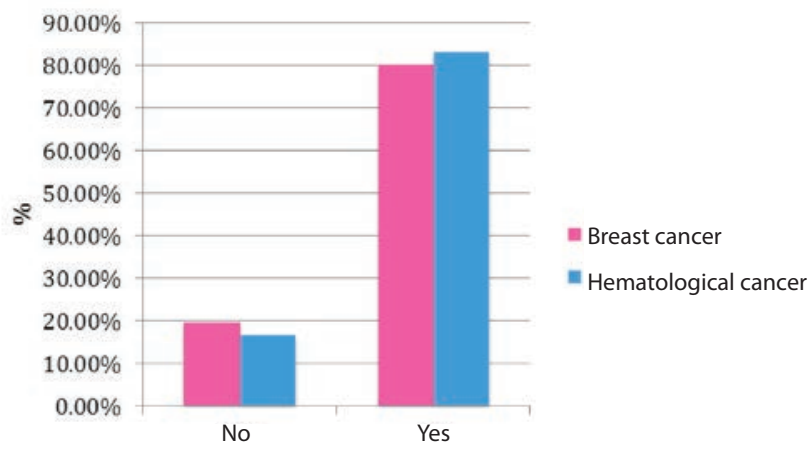

Figure 1: Usefulness of the screening questionnaire
The instrument also reassured patients on what can be done or what help was available, if desired.

S18: Yes, because after being told you have cancer, you feel overwhelmed. It was good to know that you can get help..."

Moreover, 15 participants justified their "no" by the absence of distress or feeling the need for help, as shown by these verbatim:

H5: "I said 'no' because I already knew what to expect of the hospitalization so I didn't experience any distress during my stay there."

H30: "I wasn't distressed."

S23: "Since I didn't feel anxious or any other symptom, it wasn't useful. Except, perhaps, to realize that I was handling the situation pretty well."

S67: "I didn't really need help."

However, among the "no" answers, one female participant reported that she had not received follow-up and another said that nothing had been done with her answers.

\section{Emotional discomfort at completing the instrument and the} reasons given

Again, a vast majority of patients-89.3\%, or 109 patientsdeclared that they had not found the screening for distress questionnaire to be troubling or inconvenient. Inversely, $9 \%$ of patients (11 patients) found the questionnaire to cause emotional discomfort. Two patients did not answer this question. Note that among the 11 people who answered "yes," five explained that it was because completing the questionnaire stirred emotions or caused awareness of their true feelings:

H3: "It stirs emotions. It was a necessary evil."

S69: "Even if it's useful, it was troubling at the time because it forced me to ask myself what I was experiencing. Honestly, I think that I was still refusing to admit that I had been diagnosed with breast cancer."

S70: "It's when I realized that the experience of having breast cancer could affect me and my loved ones so much."

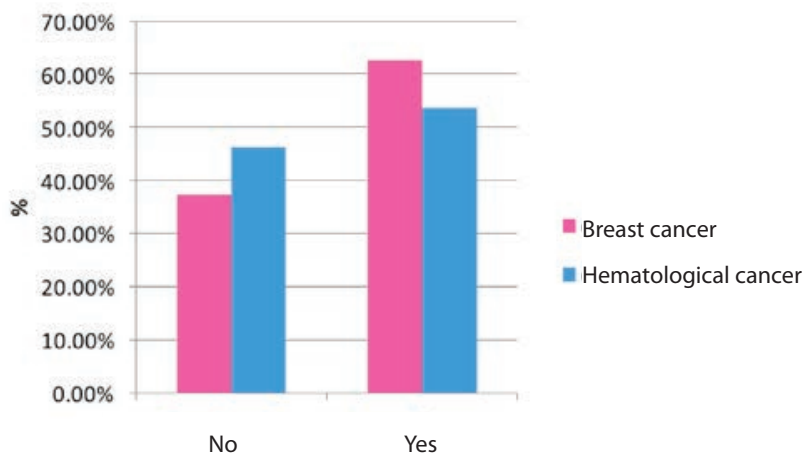

Figure 2: Discussion with a professional after completing the instrument 


\section{Help and services offered}

More than $40 \%$ (40.2\%) answered no to the question "After having completed the screening for distress questionnaire, did a professional discuss your answers with you?" Figure 2 illustrates these answers by type of cancer.

To the question "Were you offered the help you needed to meet the needs and concerns you expressed?" $71.4 \%$ of breast cancer patients and $66.7 \%$ of hematological cancer patients answered affirmatively. Therefore, $28.4 \%$ of breast cancer patients and $33.3 \%$ of hematological cancer patients were not offered the help they needed. Again, a majority of the negative answers can be explained by these patients not expressing their need for help, as the two following verbatims illustrate:

H2: "No, I always said I didn't need any specific help."

S2: "If I needed help, I would have called her for sure."

However, other people did not receive a desired response to their needs:

S9: "No one followed up with me about this. My family is supporting me, and that's already a lot."

S75: "I was referred to a psychologist, but my need was more for support from medical staff (nurse and doctor)."

To the question "Did you accept this help?," $62.3 \%$ of breast cancer patients said they accepted, while $60.9 \%$ of hematological cancer patients accepted and 36.7\% refused. See Figure 3.

Here is a glimpse of the participants' specifications:

S33: "No. But I don't really need any, for right now at least.

I'll give my turn to people who are in worse shape."

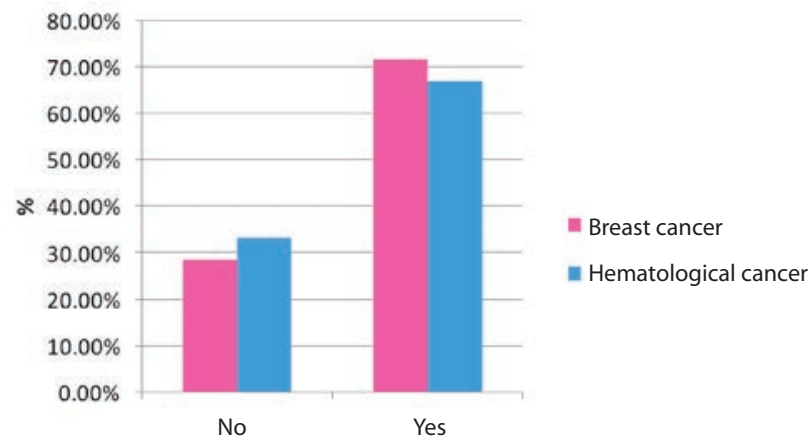

Figure 3: Suggested help perceived as adequate in response to the expressed needs

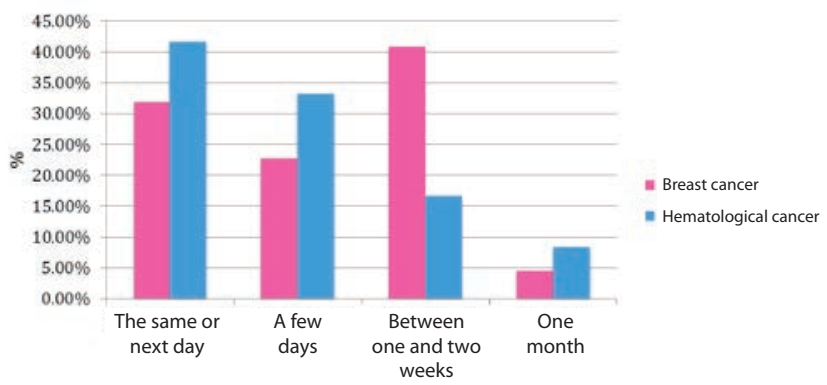

Figure 4: Delays in receiving the service
S67: "No. I was feeling strong enough and my family is here to help me through this trial."

S12: "Yes, I think the medical staff should be encouraged to offer help so it would become a habit and a reflex."

S69: "Yes, the first time I refused, but when I learned that I also had to have chemo, my nurse navigator suggested again that I meet with a psychologist. I accepted."

\section{Services received and delays}

Of the 47 patients who accepted the help, 34 received a service while 13 did not receive the offered service (27.7\%). Figure 4 shows the delays before receiving the service. More than $60 \%$ of participants received the service within a few days, and $35.3 \%$ received it the same or the next day.

\section{Overall satisfaction (Table 1)}

Only $1.6 \%$ and $3.3 \%$ of patients $(\mathrm{N}=6)$ declared being "dissatisfied" or "somewhat satisfied," respectively, by the identification of their distress and the help offered to them. Inversely, a great majority of patients claimed to be satisfied (38.5\%) or very satisfied (36.1\%). This proportion increased considerably if those who nuanced their choice of answer are excluded. We should note here that $20.5 \%$ of patients did not answer this question. See Figure 5 for the overall level of satisfaction, which for the two groups of patients is different at a threshold of $1 \%\left(\mathrm{khi}^{2}=7.236 ; \mathrm{p}=0.065\right)$.

\begin{tabular}{|l|c|c|c|c|}
\hline \multicolumn{4}{|l|}{$\begin{array}{l}\text { Table 1: What is your overall satisfaction with the identification of } \\
\text { your distress and the help offered to date? }\end{array}$} \\
\hline & Frequency & Percentage & $\begin{array}{c}\text { Valid } \\
\text { percentage }\end{array}$ & $\begin{array}{c}\text { Cumulative } \\
\text { percentage }\end{array}$ \\
\hline Valid & & & & \\
\hline $\begin{array}{l}\text { Not at all } \\
\text { satisfied }\end{array}$ & 2 & 1.6 & 2.1 & 2.1 \\
\hline $\begin{array}{l}\text { Somewhat } \\
\text { satisfied }\end{array}$ & 4 & 3.3 & 4.1 & 6.2 \\
\hline Satisfied & 47 & 38.5 & 48.5 & 54.6 \\
\hline $\begin{array}{l}\text { Very } \\
\text { satisfied }\end{array}$ & 44 & 36.1 & 45.4 & 100.0 \\
\hline Total & 97 & 79.8 & 100.0 & \\
\hline Missing & 25 & 20.5 & & \\
\hline Total & 122 & 100.0 & & \\
\hline
\end{tabular}

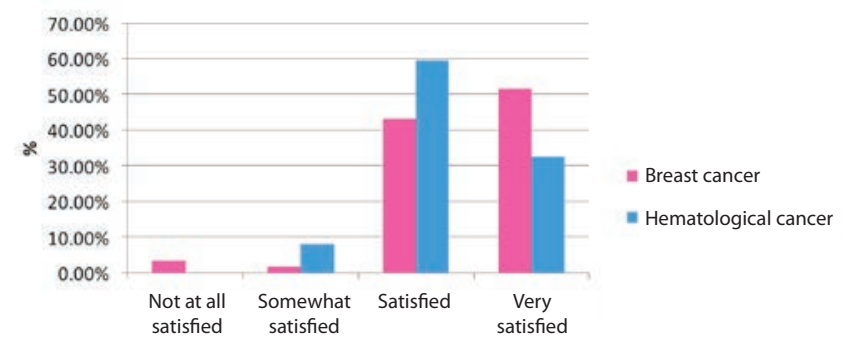

Figure 5: Overall satisfaction, according to type of cancer 


\section{Edmonton Symptom Assessment System (ESAS)}

Nearly three quarters of patients (71.35\%) entirely agreed with the statement "The ESAS is important because it allowed my healthcare team to know my symptoms and their severity." Nonetheless, more than 1 in 10 patients (13.1\%) only somewhat agreed with this statement. Table 2 shows the distribution of participant answers.

A lower proportion of patients $(57.4 \%)$ agreed with the statement "My healthcare team took my ESAS score into consideration when determining my treatment plan." Nearly $14 \%$ (13.9\%) of the sample did not answer this question. The same proportion did not have an opinion on the subject.

Figure 6 displays, according to type of cancer, the percentage of agreement with the statement "My pain and symptoms are reduced to a comfortable level." Note that $23 \%$ of the sample answered "always" and nearly $42 \%$ (41.8\%) reported "most of the time."

\section{Nurses' perceptions of screening for distress}

Meaning

Two broad thematic categories emerged from answers to the question "What does screening for distress mean to you as a nurse?" The first category encompasses various verbs used to describe the identification, evaluation, screening, and tracking of clients' problems, emotions, and concerns throughout the care trajectory that fit into a more global experience.

The second category encompasses the various verbs used to indicate the end goal of the process: help, support, and redirect to resources. Figure 7 refers to the theoretical model emerging from the meaning nurses ascribe to screening for distress, as developed by the researchers from the nurses' themes.

Table 2: The ESAS is important because it allows my healthcare team to know my symptoms and their severity

\begin{tabular}{|c|c|c|c|c|}
\hline & Frequency & Percentage & $\begin{array}{c}\text { Valid } \\
\text { percentage }\end{array}$ & $\begin{array}{l}\text { Cumulative } \\
\text { percentage }\end{array}$ \\
\hline \multicolumn{5}{|l|}{ Valid } \\
\hline $\begin{array}{l}\text { Completely } \\
\text { disagree }\end{array}$ & 1 & 0.8 & 0.9 & 0.9 \\
\hline $\begin{array}{l}\text { Somewhat } \\
\text { disagree }\end{array}$ & 3 & 2.5 & 2.6 & 3.4 \\
\hline $\begin{array}{l}\text { Somewhat } \\
\text { agree }\end{array}$ & 16 & 13.1 & 13.8 & 17.2 \\
\hline $\begin{array}{l}\text { Completely } \\
\text { agree }\end{array}$ & 87 & 71.3 & 75 & 92.2 \\
\hline No opinion & 9 & 7.4 & 7.8 & 100.0 \\
\hline Total & 116 & 95.1 & 100.0 & \\
\hline Missing & 6 & 4.9 & & \\
\hline Total & 122 & 100.0 & & \\
\hline
\end{tabular}

Figure 7: Meaning nurses ascribe to screening

The majority of nurses answered "important" to the question "Just how important do you think it is to systematically screen for patients' distress?" Indeed, $60 \%$ of nurses considered that it is important to systematically screen for patient distress, while $33.3 \%$ of nurses felt it is "crucial" and $6.7 \%$ considered it "somewhat important." It is interesting to note that no nurse reported systematic screening to be "not at all important" or "not very important."

\section{Perception of patients' perceptions}

According to our nurses, patients do not perceive the same (22.7\% of nurses). Only $11.1 \%$ of nurses considered patients perceive screening for distress with the same importance. A great proportion of nurses (64.4\%) answered "other" to this question. And the qualitative analysis of these "other" showed that almost all wrote, "It depends. For some yes, for others no." Based on participant comments, it can be deduced that nurses' perceptions of patients stem from many factors that arise in interactions or from the context, including the time of screening, the patient's attention and speed responding, the nurse's perception of the patient's interest, whether the patient feels the need for help, or refuses or accepts the referrals. Their diverse screening experiences influence these perceptions.

I8: "I think this depends on how the DST is explained and presented to the patient, as well as to the patient's state of health at arrival."

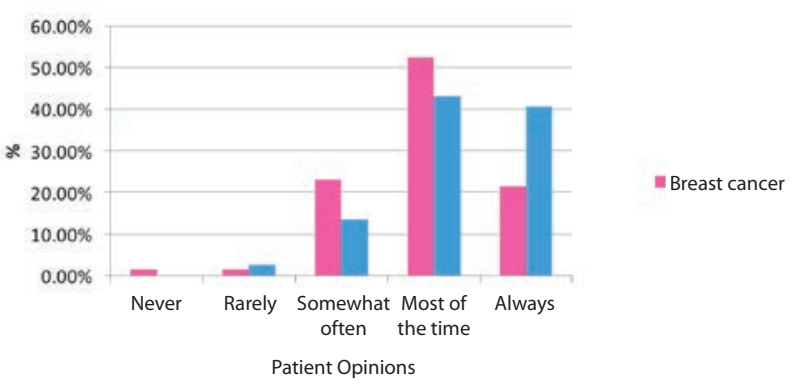

Figure 6: My pain and symptoms were reduced to a comfortable level

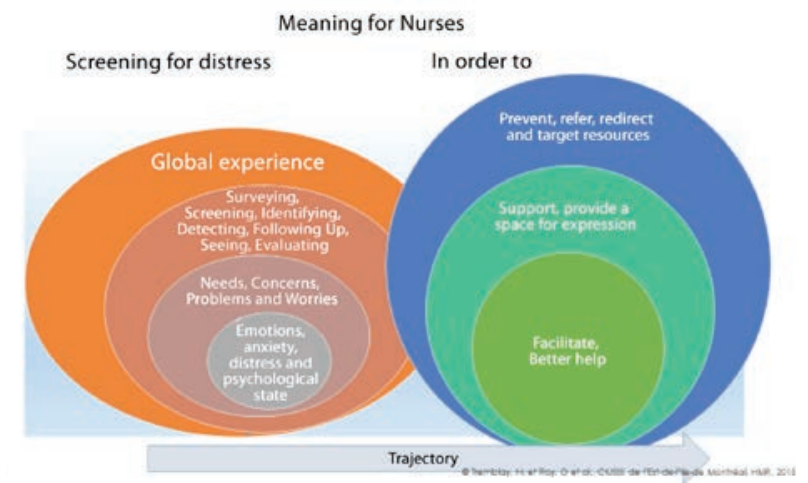
importance of systematic screening for distress as they do 
I15: "It varies greatly from one patient to another. Some find the DST important, while others seem annoyed when we present it to them."

I26: "Maybe yes for some (those who accept help more easily), but for others it's just more paperwork to fill out at a time when they already have a lot of things to manage or are already struggling to understand what's going on."

I29: "It depends on the patients. I think that even if we tell them to be sincere and that it's for them that they're filling out the DST, some will still just get rid of it or are too proud to ask for help. But this is far from the majority."

Nurses who answered "no" to this question also referred to their non-validated perceptions of patients.

I4: "No. Many people think that nothing can help them."

I17: "No, I think they think it isn't a big deal and things will blow over."

I12: "Somewhat. Some are annoyed at having to fill out this document that maybe forces them to put words on their problems. This is by self-pride or maybe because they aren't ready."

\begin{tabular}{|c|c|c|c|c|}
\hline \multicolumn{5}{|c|}{$\begin{array}{l}\text { Table 3: Perception of the usefulness of } \\
\text { Thermometer and its list of problems }\end{array}$} \\
\hline & Frequency & Percentage & $\begin{array}{c}\text { Valid } \\
\text { percentage }\end{array}$ & $\begin{array}{l}\text { Cumulative } \\
\text { percentage }\end{array}$ \\
\hline \multicolumn{5}{|l|}{ Valid } \\
\hline $\begin{array}{l}\text { Not at all } \\
\text { useful }\end{array}$ & 6 & 13.3 & 13.3 & 13.3 \\
\hline $\begin{array}{l}\text { Somewhat } \\
\text { useful }\end{array}$ & 26 & 57.8 & 57.8 & 71.1 \\
\hline Very useful & 13 & 28.9 & 28.9 & 100.0 \\
\hline Total & 45 & 100.0 & 100.0 & \\
\hline
\end{tabular}

\begin{tabular}{|l|c|c|c|c|}
\hline \multicolumn{5}{|c|}{ Table 4: Perception of the usefulness of the ESAS } \\
\hline & Frequency & Percentage & $\begin{array}{c}\text { Valid } \\
\text { percentage }\end{array}$ & $\begin{array}{c}\text { Cumulative } \\
\text { percentage }\end{array}$ \\
\hline Valid & 1 & 2.2 & 2.2 & 2.2 \\
\hline $\begin{array}{l}\text { Not at all } \\
\text { useful }\end{array}$ & 24 & 53.3 & 53.3 & 55.6 \\
\hline $\begin{array}{l}\text { Somewhat } \\
\text { useful }\end{array}$ & 20 & 44.4 & 44.4 & 100.0 \\
\hline Very useful & 45 & 100.0 & 100.0 & \\
\hline Total & & & & \\
\hline
\end{tabular}

Utility of the thermometer, the list of problems, and the ESAS

The majority of nurses (57.8\%) felt the Distress Thermometer and the accompanying list of problems was "somewhat useful." Some $28.9 \%$ found it to be "very useful" and $13.3 \%$ found it to be "not at all useful." In comparison, many fewer patients found the ESAS "not at all useful" (2.2\%). A majority of nurses considered the ESAS to be "somewhat useful" (53.3\%) and many considered it to be "very useful" (44.4\%). Tables 3 and 4 present these results.

\section{Positive and negative influences of the screening on nurses'} practice

Nurses were asked to identify from a list of statements how the screening for distress positively or negatively influenced their practice. The positive statements were that it: made for a more specific evaluation; gave more contact with people who need to manage symptoms; provided greater comprehension of what was going on with the person; made better documentation possible; and other comments (if needed). The list of negative statements included that it: takes time; collects non-relevant data; is upsetting for the patient; makes me uncomfortable as a clinician; and other comments (if needed). The proportion of nurses who found that the DST takes time was greater for those who work in walk-in oncology clinics than for those who work with a hospitalized clientele. Figures 8 and 9 show the items checked by the nurses and in what proportion.

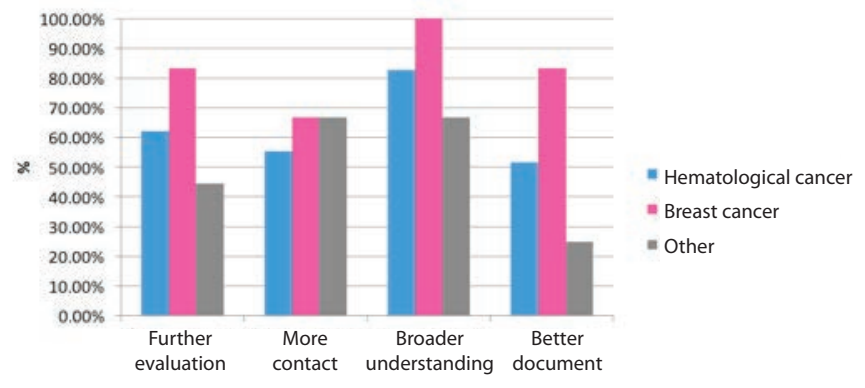

Figure 8: Positive influences of the screening on practice

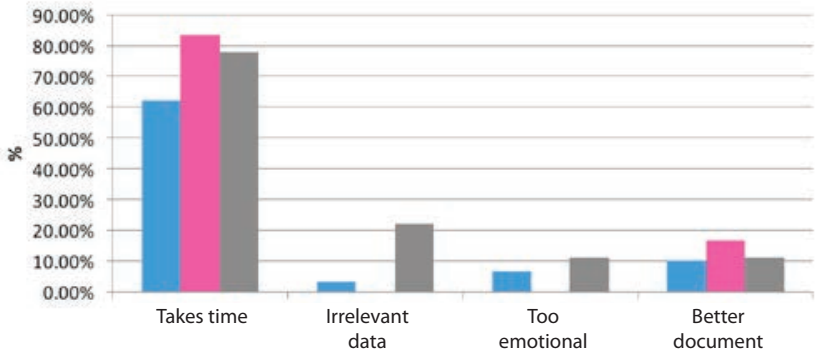

Figure 9: Negative influences of screening on practice 
Table 5: Confidence in responding to needs expressed

\begin{tabular}{|l|c|c|c|c|c|c|c|}
\hline & Information & Physical & Emotional & Psychosocial & $\begin{array}{c}\text { Resistance to } \\
\text { accepting referral }\end{array}$ & $\begin{array}{c}\text { Minority } \\
\text { groups }\end{array}$ & $\begin{array}{c}\text { Fears of mourning } \\
\text { or death }\end{array}$ \\
\hline Not at all & 4.4 & 0 & 0 & 4.4 & 4.8 & 16.7 & 4.4 \\
\hline Confident enough & 4.4 & 4.4 & 15.9 & 15.6 & 16.7 & 14.3 & 22.2 \\
\hline Somewhat confident & 15.6 & 11.1 & 29.5 & 40 & 19 & 33.3 & 28.9 \\
\hline Confident & 53.3 & 66.7 & 47.7 & 33.3 & 50 & 35.7 & 40 \\
\hline Very confident & 22.2 & 17.8 & 6.8 & 6.7 & 9.5 & 0 & 4.4 \\
\hline Total & 100.0 & 100.0 & 100.0 & 100.0 & 100 & 100 & 100 \\
\hline
\end{tabular}

\section{Referrals offered}

After the screening for distress, $86.7 \%$ of nurses suggested patients meet with a psychologist. This was the most frequently offered referral. Then, $71.1 \%$ of nurses suggested patients meet with a social worker. Less than half of the nurses offered a referral to a nutritionist (42.2\%), a clinical advisor (33\%), a doctor (26.7\%), or a physical therapist (13\%). Finally, nearly a third (31.1\%) of nurses offered another referral, be it a spiritual advisor, psychiatrist, volunteer or community group.

Confidence in the stages of screening, the problem areas and the concerns

Nurses' answers suggest that they feel more comfortable identifying and evaluating distress than responding to it and providing structured support. Therefore, they are more numerous to feel confident or very confident during the screening $(81.1 \%)$ and evaluation $(55.6 \%)$ than in responding to distress $(46.7 \%)$ or providing structured support (36.4\%). Some $13.6 \%$ report not feeling at all confident.

Interestingly, these results show that nurses feel "confident" or "very confident" in responding to informational (75.5\%) and physical $(84.5 \%)$ needs. Among these seven categories of needs, the results of the $\mathrm{khi}^{2}$ tests show that the nurses' confidence varies significantly according to their clienteles for emotional needs $\left(\mathrm{khi}^{2}=17.07 ; \mathrm{p}=0.009\right)$ and psychosocial needs $\left(\mathrm{khi}^{2}=15.82 ; \mathrm{p}=0.045\right)$.

Moreover, nurses working with breast cancer patients seem to have more confidence responding to emotional needs: $33.3 \%$ of these nurses feel "very confident" in meeting patients' emotional needs, versus $0 \%$ of nurses working with hematological cancer patients and $0 \%$ of nurses working with another clientele. This trend is the same for psychosocial needs. Indeed, 6.9\% of nurses working with hematological cell transplant patients feel "not at all confident" and 0\% feel "very confident." They feel "somewhat confident" (20.7\%) and "moderately confident" (37.9\%). Barely $34 \%$ of them feel just "confident."

Table 5 and Figure 10 display the results of the question "Just how confident do you feel responding to the needs patients express?"

\section{Nurses' screening experience}

Sixty-two percent of nurse participants had conducted at least 10 screenings with their clientele. Two nurses had

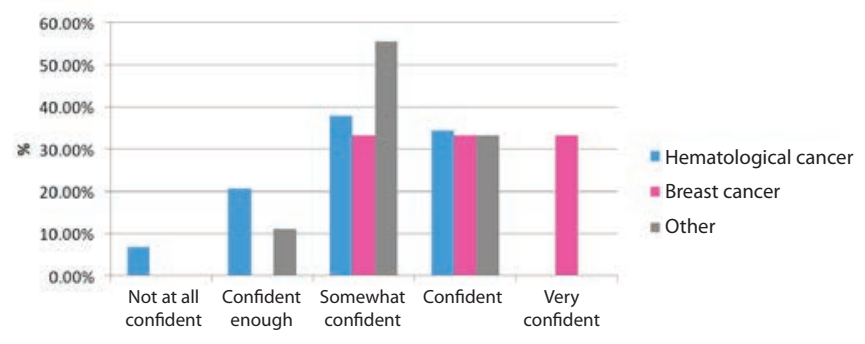

Figure 10: Confidence in responding to psychosocial needs

conducted over 100 screenings, while nine had done 20 or more. Among the others, there was a missing answer, and 15 nurses (33\%) had conducted five screenings or fewer. About $5 \%$ had done between five and 10 screenings. Nurses were also asked to report how many of these experiences were difficult and how many were positive. For $57.8 \%$ of the sample, at least one experience was more difficult than others. Three nurses did not answer this question. Among those who had conducted many screenings, only one nurse had experienced several difficult screenings, about 25 out of more than 100 . One nurse answered that both of her two screenings had been difficult.

\section{I4: "I don't feel like I have the resources."}

For $44.4 \%$ of the nurses, there were more positive than negative experiences with the screening tool, while $13 \%$ reported having had as many positive and negative experiences. Two nurses did not answer. Two others could not answer. However, $15.6 \%$ of nurses had not had a positive experience.

\section{Aspects of the screening that worked better or worse}

Among the most frequently mentioned aspects that worked well were that the screening makes it possible to identify problems more quickly and at a good time, so as to offer appropriate services, and that it allows for a greater receptivity to patients' needs, as well as better dialogue, evaluation, and follow-up. However, many nurses mentioned the lack of time for developing on the answers received, the lack of intimacy with the patient, and the moment chosen for the screening that was not favourable (for example, conducting the screening upon hospital admission, when trust with the patient had not yet been forged). 


\section{DISCUSSION}

Although there was convergence between nurses' and patients' perceptions of the importance or utility of screening for distress, there is also divergence. The quasi-totality of nurses $(93.3 \%)$ felt it is important and even crucial to conduct screening for distress. A majority of patients (81.1\%) found it to be useful. However, the study showed that just over 1 in 10 nurses (11.1\%) perceived the patient as ascribing the same importance as they to the screening. A majority of nurses (64.4\%) answered "It depends." And an analysis of nurses' perceptions shows that various patient behaviours and their interpretations feed this perception. Therefore, patients refusing to complete the questionnaire, expediting its completion and letting time go by before completing it (when given at hospital admission) are perceived as signs that the screening is not important to patients.

We reported in Part 1 of this article that a vast majority of patients indicate that they do not want to be helped with problems or worries mentioned in the DST: $77.3 \%$ at Time 1 and $85.3 \%$ at Time 2. Let us remember that, for hematological patients, Time 1 corresponds with admission to the hospital unit and, in most cases, Time 2 to hospital leave. For women with breast cancer, Time 1 corresponds to a second and third meeting after the diagnosis and Time 2 was a day during the treatment period.

Moreover, many study participants refused the referrals offered. Among the $46 \%$ of the sample offered a referral at Time 1, it was accepted $40 \%$ of the time. Without counting that, a certain proportion of patients refused to complete the questionnaire because they did not feel the need (the main reason given for refusal to complete the tool in Phase 1). Our study also showed that the most frequently given reason by patients who receive the DST but feel it is not useful is not feeling the need for it.

It is difficult to determine what effect these perceptions have on nurses in the transfer and appropriation of this practice. Although some nurses shared what does not work so well (refusal, hesitation or resistance by some patients, particularly men, to talk about their psychological pain and the need for more resources to take action), much remains to be discovered. This definitely deserves to be explored further both in research and in clinical settings, and should be an opportunity to share experiences during staff training on screening for distress. Steele and Fitch (2008) mentioned that it can be difficult for professionals to recognize cancer patients' autonomy and that these latter may decline the offered help, which can be non-desired. Some nurses also mentioned the absence of more positive screening experiences. To what should this be attributed? Inadequate preparation and training? Discomfort, embarrassment, limited beliefs about screening? Lack of cooperation? Again, there are more questions than answers. Some comments from nurse participants point to a need for training to develop greater support.

The utility of screening can also be called into doubt if the patient expresses not needing it. But what is this need exactly? Does the patient express having no need for help, no need to talk about it with us, or no distress at all? Many of the nurses' verbatims mentioned that patients did not want to be helped, which does not mean that the nurse's offer to talk or the help offered is not meaningful to them. This second phase of the study cast light on the introspective aspect of the screening that predominated in the themes on the instrument's utility for the patient. This aspect deserves exploration in future research.

The analysis also showed that, for the most part, patients and nurses share the same comprehension of the goal of the tool (identifying concerns and problems that could interfere with well-being and that should prompt further emotional support and symptom management).

Clover, Mitchell, Britton, and Carter (2014) conducted a study to understand why patients in walk-in oncology clinics who reported emotional distress ( 4 and up on the DT) refused help. In their study, $71 \%$ of the sample $(\mathrm{N}=311)$ refused the help offered. Our study reported $77.3 \%$ of participants who did not want to receive help. However, this last number makes no distinction between those who reach the clinical score and those who do not. The reasons participants in the study by Clover et al. gave were that they prefer managing it alone (46\%), they are already receiving help (24\%), and their distress is not great enough (23\%). These last two themes were also found in many of our study participants' verbatims. Another recent study by Tuinman, Van Nuenen, Hagedoorn, and Hoekstra-Weebers (2015) presents similar results. In this study, $67 \%$ of patients did not wish to receive a referral and an additional 20\% said "maybe" $(\mathrm{N}=1340)$. It was among single people that the wish to receive help was the highest. They were twice as likely to accept a referral as married patients. Johnnson's 2010 study, as cited in VanHoose et al. (2015) indicates, moreover, higher rates of distress among single women. Might we see in these findings the protective role for psychological health of the presence of a life partner? Partners are known to offer positive interactions, and emotional and social support that attenuates distress (Canadian Institute for Health Information, 2012). But who is supporting the family who is supporting the patient? The need to screen for distress in caregivers is increasingly felt, as screening becomes systematic with cancer patients (Direction générale de cancérologie, 2015).

Clover's study also revealed that among those who feel their distress is insufficient to ask for help, $18 \%$ scored 8 or higher. Other studies should be conducted on this subject. The stigma associated with psychological help has been amply described, but its presence has a less negative influence with cancer (Clover et al., 2013, as quoted in Clover et al., 2014). Moreover, Salmon, Clark, McGrath, and Fisher (2015) warn that it can be harmful to patients to tell them they need help based on their answers. These authors also report study findings that indicate that, among those who experience emotional distress, less than half have sought or intend to seek help. And in another study quoted in Salmon et al. (Shimizu et al., 2010), less than a quarter accepted the referral to see a psycho-oncologist. In light of our and others' findings, it would appear to us, as clinicians, that a referral should not be encouraged as the only possible response to a high score. Instead, this could be a poignant moment either to highlight a strength or to reflect on a 
legitimate desire of the patient. As these authors mention, a positive screening should not be interpreted as an obligation or an expectation of patients to accept formal help. Analysis of their perceptions leads us to believe that for some people, screening does not have the same value. These avenues remain to be explored.

Our findings also shed light onto the fact that symptom management was very little addressed in our written comments from both patient and nurse participants. It should be noted that the majority of patients in Phase 2, like in Phase 1, was solicited at the beginning of their trajectory, or a moment when the symptom-related load is perhaps the least high (Baba, Fransson, and Lindh, 2007).

Scales such as ESAS were developed to facilitate clinical practice and measure care results (Baba, Fransson, \& Lindh, 2007). A Swedish study reports, as we did, that caregiving staff considers the ESAS to be a good instrument to obtain information regarding patients' symptoms, but that according to nurses, it is not useful during medical visits (Baba et al., 2007).

Our results show that when missing data are excluded, symptoms are either "always" $(27.7 \%)$ or "most of the time" $(50.5 \%)$ reduced to a comfortable level. Nonetheless, more than one in five patients is at best comfortable "often enough." One person stated "never" and two "rarely." Although the sample was small, can we do better or is discomfort inevitable? In implementing the DST in our establishment, we saw repeatedly that symptom management, particularly its evaluation and documentation, is not always optimal to ensure continuity of care. Although physical comfort has long received attention in oncology, there is still room for improvement in the area.

On another note, we were surprised by the high percentage of cancer patients (40.2\%) who reported the absence of discussion with a professional after having completed the tool. Although a different interpretation of the question could have occurred to explain this result (please see the Limitation section of this article), we must also admit that the desired discussion did not always occur. Yet, this feedback is undoubtedly the DST's most crucial aspect, which is stressed in the training of screening professionals (Fillion et al., 2011). How can this be explained? Time (or lack of time) for the screening was mentioned spontaneously verbatim by more than four in 10 nurses (42.2\%), and a great majority of them also identified the lack of time as an element with negative influence on using QNP. Nurses also named lack of time at all the stages of implementing the tool and all the stages of our study. This lack of time was also reported by different researchers (Absolom et al., 2011; Asselin, 2012; Arantzamendi \& Kearney, 2004; Fillion et al., 2011; Mitchell, Kaar, Coggan, \& Herdman, 2008). Screening occurs against a backdrop in which nurses are constantly rushed, which perhaps explains in part the findings. Patients also perceive a lack of time, which may lead some to choose to keep quiet, as certain clinical observations lead us to believe. Moreover, other studies also pointed to the ambiance in chemotherapy rooms-an environment that is not conducive to intimacy (Arantzamendi \& Kearney, 2004)—and nurses are among the most sensitive professionals to this aspect (Absolom et al., 2011).
Our proposed theoretical model on the meaning nurses ascribe to screening tends to indicate that nurses are greatly in favour of screening for distress, but feel that it must fit into the realities of their practice that are conducive to this process. This proposal deserves to be included in clinical practice and training, and should be further developed by other studies.

Moreover, this theoretical proposal does not account for the introspective nature of the screening mentioned by patient participants. This bit of understanding deserves our full attention in clinical practice.

Our study also shows nurses have little confidence in responding to distress and providing patients with structured support, as these responses fall into the psychosocial and emotional areas in which nurses feel less confident. Moreover, a majority of referrals are to psycho-oncologists (86.7\%). On this topic, Fillion et al. (2011) mentioned the success of implementing screening for distress as a key element in an effective training of healthcare workers.

\section{Limitations in Phase 2}

The greatest limitation in Phase 2 was the non-validation of the questionnaires before the study was launched. Although all members of the research team were familiar with the two questionnaires and gave their opinions on content and question phrasing, and although these two questionnaires were based on others used in other studies or surveys, certain methodological elements were not anticipated. For example, Question 6 of the QPP could be read as follows: "After having completed the screening for distress questionnaire, did a professional discuss your answers with you?" The choice of answer was yes or no, and no additional space was provided for specifications or comments. The surprisingly high proportion of negative answers (40\%) leads us to believe that question was perhaps poorly interpreted. For example, were patients expecting to have a discussion with a professional other than the nurse, even if such a need was not articulated or identified after the screening?

Furthermore, Question 7 of the QPP asked patients if they had been offered the help they desired in response to the needs and concerns they expressed. However, if the patient did not feel she or he had received help, or had not expressed a specific concern, it was difficult to answer by yes or no. Luckily, as most respondents wrote in the margins and in the "Please specify" section, we were able to understand or interpret their perceptions of the situation.

The QNP also had a question that was subject to various interpretations. Question 11 asked nurses the number of times they had used the DST to conduct screening for distress. Some nurses answered in proportions $(75 \%, 1 / 6$ or $1 / 2)$, making their answers somewhat difficult to evaluate in terms of their user experience with the tool. We would have gained in validating our questionnaires beforehand. Since the number of nurses dedicated uniquely to breast cancer patients was very low (6), we had to be excessively cautious in comparing the various groups of nurses. 


\section{CONCLUSION}

The results of our study's Phases 1 and 2 confirmed and developed various aspects of screening for distress. Offering screening for distress not only allows us to offer a response, it also and especially allows us to adapt our offer. A recent study (VanHoose et al., 2015) shows that some problems lead more to distress. Financial issues, concerns, worries, anxiety and trouble sleeping are some of the problems that deserve more attention. Future studies might further explore offering more help in these situations. Our results will make it possible to pursue the implementation of screening in our establishment. We must also review our understanding of the tool's end purpose with the two groups of participants. The introspective value of screening for the patient makes sense with

\section{REFERENCES}

Absolom, K., Holch, P., Pini, S., Hill, K., Liu, A., Sharpe, M. Richardson, A., \& Velikova, G. (2011). The detection and management of emotional distress in cancer patients: The views of health-care professionals. Psycho-Oncology, 20, 601-608. doi:10.1002/pon.1916

Admiraal, J.M., van Nuenen, F.M., Burgerhof, J.G.M., Reyners, A.K.L., \& Hoekstra-Weebers, J.E.H.M. (2016). Cancer patients' referral wish: Effects of distress, problems, socio-demographic and illnessrelated variables and social support sufficiency. Psycho-Oncolog, $Y$ 25(11), 1363-1370. doi:10.1002/pon.4067.

Alberta Health Services (2012 A). Evaluation tool: Baseline. Patient perception of care quality. Instrument developed by Teno, J., Boston University, toolkit of instruments adapted by Cancer Care Ontario.

Alberta Health Services (2012B). Final Clinician Survey. Modified from BC proof of concept Project with permission. Component of evaluation around confidence with distress assessment and topics adapted from IPODE final course evaluation with permission.

Arantzamendi, M., \& Kearney, N. (2004). The psychological needs of patients receiving chemotherapy: An exploration of nurse perceptions. European Journal of Cancer Care, 13, 23-31. doi:10.1111/j.1365-2354.2003.00438.x

Asselin, P. (2012). Perceptions des infirmières en hémato-oncologie ambulatoire face au dépistage systématique de la détresse et à ses effets sur les soins centrés sur la personne. Présentation faite dans le cadre de la journée scientifique de l'Association québécoise des infirmières en oncologie (AQIO), le vendredi 23 novembre 2012.

Baba, K., Fransson, P., \& Lindh, J. (2007). Use of a modified ESAS in cancer patients: A pilot study of patient and staff experiences. International Journal of Palliative Nursing, 13(12), 610-616.

Blais, M.C. (2012). Perceptions des infirmières en hémato-oncologie ambulatoire face au dépistage de la détresse. Volet B. Présentation faite dans le cadre de la journée scientifique de l'Association québécoise des infirmières en oncologie (AQIO), le vendredi 23 novembre 2012.

Canadian Institute for Health Information. (2012). Le rôle du soutien social dans l'atténuation de la détresse psychologique. https:// secure.cihi.ca/free_products/AiB_ReducingPsychological\%20 DistressFR-web.pdf, pages récupérées le 2 août 2016. their desire to turn to their personal resources, and professionals could further respect this. Conversely, the desire not to receive help deserves to be explored further, particularly with men. The interview-based Phase 3 will focus on this theme in particular.

\section{ACKNOWLEDGEMENT}

This article presents the findings of the second phase of a study with an exploratory sequential mixed research design (Creswell Q Plano Clarke, 2007) on the systematic screening of distress. It was made possible by financial support from the Canadian Association of Nurses in Oncology and the Fondation de l'hôpital Maisonneuve-Rosemont, a fund administered by the hospital's Centre d'excellence en soins infirmiers.

Clover, K.A., Mitchell, A.J., Britton, B., \& Carter, G. (2014). Why do oncology outpatients who reported emotional distress decline help? Psycho-Oncology, 24(7). doi:10.1002/pon.3729

Creswell, J.W., \& Plano Clark, V.L. (2007). Designing and conducting mixed methods research. Thousand Oaks, CA: Sage Publications.

De Marinis, M.G., Piredda, M., Chiara Pascarella, M., Vincenzi, B., Spiga,F., Tartaglini,D., Alvaro, R., \& Matarase, M. (2010). If it is not recorded, it has not been done!? Consistency between nursing records and observed nursing care in an Italian hospital. Journal of Clinical Nursing, 19, 1544-1552. doi:10.1111/j.1365-2702.2009.03012.x

Direction générale de cancérologie (2015). Comité ad hoc sur l'utilisation de dépistage de la détresse pour la clientèle en cancérologie. Diverses communications personnelles entre membres du comité.

Fillion, L., Cook, S., Blais, M.-C., Veillette, A.-M., Aubin, M., de Serres, M., et al. (2011). Implementation of screening for distress with professional cancer navigators. Oncologie (Dossier Après Cancer), 13, 277-289. doi:10.1007/s10269-011-2026-8

Foss, C., \& Ellefsen, B. (2002). The value of combining qualitative and quantitative approaches in nursing research by means of method triangulation. Journal of Advanced Nursing, 40(2), 242-248.

Mitchell, AJ., Kaar, S. Coggan, C., \&, Herdman, JA. (2008). Acceptability of common screening methods used to detect distress and related mood disorders-preferences of cancer specialists and non-specialists. Psycho-Oncology, 17(3), 226-236. http://onlinelibrary.wiley.com/doi/10.1002/pon.1228

Salmon P., Clark L., McGrath E., \& Fisher P. (2015). Screening for psychological distress in cancer: Renewing the research agenda, Psycho-Oncology, 24(3), 262-268. doi:10.1002/pon.3640

Steele, R., \& Fitch, M.I. (2008). Supportive care needs of women with gynecological cancer. Cancer Nursing, 31(4), 284-291.

Tremblay, N., Roy, O., \& Lecocq, A. (2017). Systemic screening of distress: Portraits and cross-examination of the various stakeholders' perceptions, clinical perspectives, and researchPart 1. Canadian Oncology Nursing Journal, 27(3), 224-235.

Tuinman, M.A., Van Nuenen, F.M., Hagedoorn, M., \& HoekstraWeebers, J.E.H.M. (2015). Distress, problems and referral wish of cancer patients: Differences according to relationship status and life phase. Psycho-Oncology, 24(6), 699-704. doi:10.1002/pon.3712

VanHoose, L., Black, L.L. Doty, K., Sabata, D., Twumasi-Ankrah, P., Taylor, S., \& Johnson, R. (2015). An analysis of the distress thermometer problem list and distress in patients with cancer. Support care cancer, 23(5), 1225-1232. doi:10.1007/s00520-014-2471-1 


\title{
Adapting and applying the Synergy Model on an inpatient hematology unit
}

\author{
by Yayra Amenudzie, Georgia Georgiou, Enoch Ho and Elizabeth O'Sullivan
}

\begin{abstract}
A pilot project was undertaken by an inpatient hematology and hematopoietic stem cell transplant unit to determine the feasibility of adapting the Synergy Model (Curley, 2007; 1998) to this patient population. During phase one, a patient characteristic tool for measuring complexity, stability, predictability, and participation in care was developed and tested. The tool was found to have strong face validity, high internal consistency, strong construct validity, and moderate inter-rater agreement. A nurse competency assessment was also developed, along with processes for making nursing and Health Care Aid assignments, as well as staffing decisions. The results of the pilot demonstrated that the Synergy Model can be adapted to this population and that it is feasible to use the model in an acute inpatient setting.
\end{abstract}

\section{BACKGROUND AND PURPOSE}

The malignant hematology/Hematopoietic Stem Cell 1 Transplant (HSCT) inpatient unit at the Juravinski Hospital underwent a transformational change that brought together two clinical teams, equipment, and support services. While the transition was successful on several fronts, the large physical footprint of the unit, the high patient acuity, the large number of novice nurses, different nursing practices between the two clinical teams, and limited Health Care Aid (HCA) resources (one HCA per shift for 39 patients), proved to be extremely challenging when it came to making

\section{ABOUT THE AUTHORS \\ Yayra Amenudzie, RN, MN, CON(C), Hematology Nurse \\ Georgia Georgiou, BA, MEd, Clinical Manager, Stem Cell Transplant Program \\ Enoch Ho, MPh, RPT, RAcu, Quality \& Value Improvement Office; hoenoch@HHSC.CA, T: 905.521 .2100 ext. 42097 \\ Elizabeth O'Sullivan, RN, BScN, MScN, Director, elizabethosullivan29@gmail.com \\ Address for correspondence: Georgia Georgiou, BA, MEd, and Yayra Amenudzie, RN, MN, Ron and Nancy Clark Hematology Unit, Juravinski Hospital and Cancer Centre, Hamilton Health Sciences, 699 Concession Street, Hamilton, ON L8V 5C2}

(905) 521-2100 ext 43910

E-mail: georgg@hhsc.ca or amenudzie@hhsc.ca

DOI: $10.5737 / 23688076274338342$ nursing and HCA assignments. There was inconsistency in how assignments were made from one shift to the next, which was causing friction among team members, complaints about workload, and unsafe assignments that put both patients and staff safety at risk. The high nursing workload, patient acuity, and a very heterogeneous nurse competency were negatively affecting teamwork, morale, the quality of patient care, patient and staff satisfaction, recruitment, and retention. The team identified the need to improve the work environment by developing an objective staffing decision-making model that takes into consideration not only the acuity of patients, but also the competency of the nurse.

A mandatory nurse-to-patient ratio or patient classification systems have been proposed, as approaches to ensure adequate nurse staffing. However, a literature review found that a method of staffing that incorporates unit nurses' direct input into daily staffing decisions is warranted, as there are many variables that impact daily staffing decisions (Hertel, 2012).

This observation led our team to pilot the Synergy Model for a number of reasons. First, the Synergy Model is a nurse-driven professional practice model that empowers nurses by enabling them to have control over their practice and work environment (MacPhee, 2011). Secondly, the model focuses on the patient's needs when determining the nurse competency requirements and resources requirements. Although the model originated in an acute and critical care setting, it has been applied in diverse settings and for multiple purposes. Published research suggests the model has the potential to transform the way healthcare providers think about patients and the method for making patient assignments. It provides a means for care providers to determine their patients' needs and the healthcare provider best suited to meet those needs, so that the best possible outcomes for the patients are achieved. While the Synergy Model has been shown to be beneficial in various healthcare settings with different patient populations (Carter \& Burnette, 2011; Pope, 2002; Gralton \& Brett, 2012; Kaplow \& Reed, 2008), we were unable to find any applications of the model in a Canadian inpatient hematology and stem cell transplant unit.

The purpose of the pilot project was to examine the feasibility of adapting the Synergy Model to make nursing assignments in a hematology/ oncology patient population and to evaluate its usefulness and impact. This paper focuses on the first phase of the pilot, which involved answering three questions: Can the Synergy Model be adapted for a hematology patient population? Is it possible to implement the model in an acute inpatient setting? What challenges are encountered and what strategies facilitate successful implementation? The second phase of the pilot, which is described elsewhere, involves an evaluation of the model's usefulness and impact on care delivery and practice. 


\section{METHODS}

A Synergy Work Group was formed to lead the pilot. The work group consisted of five registered nurses, a nurse practitioner, an HCA, the unit Clinical Educator, a Clinical Manager, the Program Director, a Quality Specialist, an Interprofessional Practice Chief, ad hoc input from physicians, and executive sponsorship from the Vice President of Interprofessional Practice and Chief Nursing Executive. Funding from two grants was obtained to enable a front-line nurse to have dedicated time to lead the project as a Synergy Coach. The Provincial Nursing Workload Project Resource Toolkit, which describes the British Columbia Nurse's Union (BCNU) use of the synergy model (BCNU, 2010), was also used as a guide.

This study used a Participatory Action Research (PAR) approach in which qualitative, as well as quantitative methods were used. The aforementioned Synergy Work Group actively participated in the development of the tool and the implementation process. Monthly group meetings were held with this core group to analyze the data collected from interviews, focus groups and surveys. One exit interview was held with the unit leader who led the implementation. Five hundred and sixty-eight nursing surveys, as well as 73 Unit Leader surveys were completed and were analyzed using statistical measures to ascertain reliability, validity, consistency and significance. Staff members were invited to complete a survey of the work environment prior to the start of the pilot. Common themes were extracted from the focus groups, surveys and interviews.

The section below outlines the methodology used to 1) assess the current state of the work environment, 2) develop and validate a patient characteristic tool for our patient population, 3) develop a nurse competency assessment for oncology nurses specializing in hematology and stem cell transplantation, 4) develop staffing guidelines, and 5) evaluate whether the tools and processes can be implemented.

\section{Instrument Development: Patient Characteristics Tool}

Our environmental scan highlighted the importance of developing tools and processes that were simple and efficient to use in daily practice. The work group used a Socratic, consensus-based decision-making process to generate patient markers that defined each of the eight patient characteristics for haematology. The group reviewed each marker and flagged those that appeared under more than one patient characteristic. These markers were then aligned with the most appropriate patient characteristic. The final "best" characteristics that were felt to reflect our patient's needs were selected. In order to simplify the tool, the work group chose to use a three-point rating scale instead of a five-point scale, with level 1 representing the most acute and level 3 being the least acute. Finally, the work group also chose to report each individual score for each characteristic rather than compute an average score as described in the original model.

To assess the face validity of the tool, three clinical experts (hematologists) reviewed the tool and provided feedback on how well each marker aligned with each patient characteristic and whether any markers or characteristics were missing or unnecessary. The physicians had no involvement in developing the tool and no familiarity with the Synergy Model. The tool was applied to real case studies to further assess face validity.

To test the construct validity of the tool, two hematologists who were unfamiliar with the Synergy Model, were asked to rate patients under each characteristic during their rounds, using a five-point scale. They based their ratings on their routine patient assessment and clinical judgment. At the same time, an expert nurse rated the same patients separately from the physicians. The physician and nurse were blinded to each other's assessment results and their results were compared using the Pearson Correlation test.

Lastly, the internal consistency and inter-reliability of the tool were also determined using Cronbach's Alpha and Intra-Class Correlation (ICC) test, respectively. The inter-reliability of the tool was tested by having three expert hematology nurses independently rate the same patients while being blinded to each other's ratings.

\section{Instrument Development: Nurse Competency Assessment}

A nurse competency assessment was developed based on Benner's model (1984), the Canadian Association of Oncology Nurses standards (2002), as well as the nurse characteristics outlined in the Synergy Model (Curley, 2007). All hematology nurses completed the self-assessment and were categorized as novice, advanced beginner, competent, proficient, or expert.

\section{Process Development: Assignments \& Staffing Guidelines}

Guidelines for making the nursing assignments did not exist in our unit and needed to be developed. The guidelines needed to specify the type of patients (level of acuity) and the number of patients a nurse can be assigned, based on the nurse's competency. Given the fluctuating acuity of hematology patients and the need for increased monitoring and nursing interventions, it was evident that there would be times when additional resources would be needed in order to meet the staffing guidelines. Senior leadership approval and backing was obtained for the development of criteria to be used for requesting additional nursing and/or HCA resources, based on patient acuity scores.

To develop the staffing guidelines, nurses were asked to complete a survey on every day shift for three weeks, which involved rating their assignment as a) ideal work pace enabling them to go above and beyond, b) busy but manageable, c) busy and barely manageable, or d) unmanageable and unsafe. They were also asked to indicate whether the acuity scores reflected the actual acuity of the patient and to record their level of nurse competency. A similar process was used to develop staffing guidelines for assigning the HCA. These data were then used to develop guidelines for making assignments and for defining the thresholds for additional staffing.

Two focus groups provided input on how to design the daily operational processes for scoring patients, submitting the scores, updating the scores, making the assignments, and for requesting additional resources. The sampling for the two focus groups was purposeful and included nurses from each nursing rotation. Staff education on the tools and processes 
was provided through educational retreats and one-to-one coaching. It was decided that patients would only be scored on day shifts during the pilot to ensure the necessary supports were in place to facilitate successful implementation.

\section{Methods for Evaluating the Model's Applicability}

The following measures were selected to determine whether the newly developed tools and processes could be applied: a) percentage of time the patient acuity tool was completed by nurses, b) percentage of time the patient acuity scores and staff competencies were used to make the nursing assignment, c) how often the criteria were met for increasing staffing levels, and d) barriers and enablers to implementation. These data were collected over 73 day shifts, from January 13 , 2014-March 31, 2014, and were obtained using a daily nurse survey, daily unit leader survey, focus groups, and a 1:1 interview with the Unit Leader.

\section{RESULTS}

In total, 568 nursing surveys, 73 Unit Leader surveys, staff comments from two focus groups, and one interview with the Unit Leader were collected and analyzed. The results are discussed, as they relate to each of the pilot project questions.

\section{Question 1: Can the model be adapted for hematology patients?}

A hematology patient acuity tool was developed for our patient population comprising four characteristics: participation in care, predictability, complexity, and stability (See Figure 1).

The hematology experts agreed on the four characteristics and the markers within each characteristic, indicating strong face validity. An analysis of the data obtained from the daily nursing survey indicated that $94 \%$ of nurses felt that the synergy scores accurately reflected patient acuity. The results of the internal consistency test revealed a Cronbach Alpha of greater than 0.88 for all four patient characteristics (complexity $=0.89$; stability $=0.95$; participation in care $=0.89$; predictability $=0.87$ ). This suggests that all items consistently measure the underlying construct, and they all offer something unique.

The tool was also found to have good construct validity. The Correlation Coefficients for each domain were Complexity $=.72$; Predictability $=.77$; Participation in care $=.75$; Stability $=0.54$. The results for the inter-rater reliability test of the tool using ICC were greater than 0.7 for all characteristics, indicating substantial to almost perfect agreement between raters $($ Complexity $=0.81$; Stability $=0.92$; Participation in care $=0.77$; Predictability $=0.71$.

\section{Question 2: Can the model and processes be applied?}

The tools and process were applied consistently, the majority of the time. RNs used the synergy patient characteristics tool to score patients $77 \%$ of shifts and the Unit Leader used the scores to make the assignment $100 \%$ of shifts. An additional HCA was needed for 27 shifts and an additional registered nurse was needed on 23 shifts. However, it was not always possible to increase staffing when needed because staff were either unavailable or overtime costs would be incurred.

\section{DISCUSSION}

\section{Limitations of the model}

The model is designed to measure patient acuity, not workload. However, workload must also be considered when making the assignment. One drawback of changing the acuity scale from a five-point scale to a three-point scale is that the tool is less sensitive in picking up differences that affect workload. For example, two patients may have the same scores, but require different nursing interventions that take more or less time. The tool could be improved by capturing interventions that require closer monitoring and nursing care.

Although the Synergy Model provides a more objective way for making the nursing assignment, the process is time-consuming, complex and intimidating. It requires synthesizing four scores for 39 patients and consideration of other factors (e.g. continuity of the assignment, geography, etc.). Having a consistent Unit Leader for six to eight months provided the opportunity for ample practice. Adequate training is also needed to enable nurses to become confident in making assignments using the synergy scores.

Achieving compliance with daily scoring and updating scores when acuity changes requires constant reinforcement and is possible with the right prompts and accountability structures in place. To achieve a good match between patient needs and nurse competency, it is necessary to have an appropriate nursing skill set on every shift with a sufficient cross-section of competent, expert, and proficient nurses. When there is a disproportionate number of novice and advanced beginners in a rotation, it is difficult to meet the staffing guidelines. Nonetheless, the model can help inform recruitment decisions, optimal configuration of the master rotation, and nursing professional development planning. Finally, if the model is to be used to make staffing adjustments, leadership support and budget must be obtained up-front and a large enough pool of part time on-call staff is needed in order to avoid incurring overtime costs.

\section{Enablers for Implementation}

The responses from the focus groups, surveys, and interviews pointed to several enablers that facilitated successful implementation: a) backing and sponsorship from the hospital's senior leadership; b) strong project management and a clear plan to stay on track and on budget; c) access to funding that enabled a front-line nurse to lead the pilot and to engage front-line staff; d) having a Unit Leader with strong leadership skills; e) access to Quality Specialists, Practice Chiefs, and experienced researchers for guidance and mentorship; f) access to funding to support staff education on the new tool and processes; g) frequent auditing of data to ensure data integrity; and $h$ ) process in place to regularly update $\mathrm{RN}$ competencies.

\section{CONCLUSION}

The results of our pilot project affirm that the Synergy Model can be adapted to different patient populations, as purported by others (MacPhee et al., 2011; Kaplow \& Reed, 2008; Kerfoot et al., 2006; MacPhee et al., 2010). The application of 
Figure 1. C4 Hematology Patient Acuity Tool

Name

C4 HENATOLOGY PATIENT ACUITY TOOL - SYNERGY MODEL $\mathrm{Rm}$

Do not duplicate without pemission Date

Please Refer to the "Defined Ierms section" for any words with an asterisk "(Defined terms avalable on share drive or laminated form found on cork bourd at each station).

Level $1 \rightarrow$ Highly acute $\quad$ Level $2 \rightarrow$ Moderately acute

Level $3 \rightarrow$ Least acute

* We are scoring patients to reflect their current needs unless it explicitly states "next shift".

* Palliative* patients: do notneed to be scored understability.

\section{A-STABLITY}

\begin{tabular}{|c|c|c|}
\hline $\begin{array}{l}\text { Lerel l(at least } 2 \text { of the } \\
\text { criteria; if one criteria only } \\
\text { then pt is level 2) }\end{array}$ & $\begin{array}{l}\text { Lerel 2 (at least } 2 \text { of the } \\
\text { criteria OR only one in } \\
\text { level } 1 \text { and one in level 2) }\end{array}$ & Letel 3 \\
\hline DActrvay blasding & 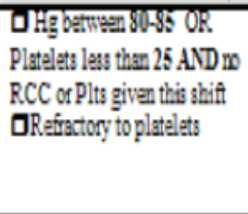 & 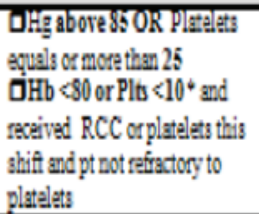 \\
\hline $\begin{array}{l}\text { D.More than } 2 \text { lab value" } \\
\text { imbalances requiring } \\
\text { interventions not including } \\
\text { blood products transfusions }\end{array}$ & $\begin{array}{l}\text { DOnes two lab valug" } \\
\text { imbalances requiring } \\
\text { intervantion not including } \\
\text { blood products transfusions }\end{array}$ & 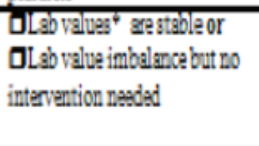 \\
\hline $\begin{array}{l}\text { D.Nectroperic and } \\
\text { Temperture more then } 38\end{array}$ & $\begin{array}{l}\text { DNeutropence No Temp. } \\
\text { a Not Neutropenic but has } \\
\text { temperature }\end{array}$ & $\begin{array}{l}\text { D.NoNeutroperia and No } \\
\text { temperature }\end{array}$ \\
\hline $\begin{array}{l}\text { UNew" onsat of ungtable } \\
\text { vitals" and requining } \\
\text { interventions (vitals not } \\
\text { within pt's nom; excluding } \\
\text { temp.) }\end{array}$ & $\begin{array}{l}\text { QVitals }{ }^{4} \text { stable with } \\
\text { intervantions ( } \mathrm{O}_{2} \text { included) } \\
\text { aUnstable vitals }{ }^{4} \text { with } \\
\text { ongoing monitoring and } \\
\text { intervantion }\end{array}$ & $\begin{array}{l}\text { QVitals stable, a within } \\
\text { patient's nom. No interventoss } \\
\text { sequired }\end{array}$ \\
\hline 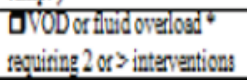 & $\begin{array}{l}\text { OFlwid ovelosd reaguing } \\
\text { onsintervation }\end{array}$ & 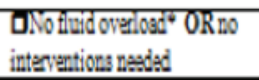 \\
\hline 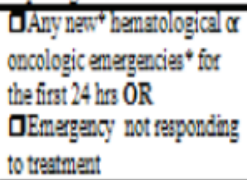 & $\begin{array}{l}\text { DAnyidentified } \\
\text { bematological or oncologic } \\
\text { emergencies" which is } \\
\text { improving on treatment }\end{array}$ & $\begin{array}{l}\text { DNo hematological of } \\
\text { oncologic energancias" }\end{array}$ \\
\hline $\begin{array}{l}\text { DAltred cognition reguifing } \\
\text { 1:1 }\end{array}$ & $\begin{array}{l}\text { DAlitered cognition butesaly } \\
\text { redireted }\end{array}$ & DAlent and ofientated $x^{3}$ \\
\hline
\end{tabular}

D- PARTICPATION NCARE*

\begin{tabular}{|c|c|c|}
\hline $\begin{array}{l}\text { Lerel l( at least } 2 \text { criteria; } \\
\text { if only } 1 \text { then pt is level 2) }\end{array}$ & $\begin{array}{c}\text { Lerel 2 (at least } 2 \text { of the } \\
\text { criteria) }\end{array}$ & Lerel 3 \\
\hline $\begin{array}{l}\text { DPt unable to periom any } \\
\text { ADLs }\end{array}$ & $\begin{array}{l}\text { DRequires assistance with } \\
\text { ADLs }\end{array}$ & Dlindependent with ADLs \\
\hline $\begin{array}{l}\text { DPt dependent on stafif and } \\
\text { sastoted devicast for toileting }\end{array}$ & $\begin{array}{l}\text { UUgas asisted devica for } \\
\text { toileting independantly. }\end{array}$ & $\begin{array}{l}\text { Dlindpandent with tolleting } \\
\text { without assisted dericas. }\end{array}$ \\
\hline $\begin{array}{l}\text { DBedrest, cheir fast of } \\
\text { immobile, } 2 \text { penon asaist }\end{array}$ & $\begin{array}{l}\text { Ol perton assist with } \\
\text { mobilization }\end{array}$ & $\begin{array}{l}\text { Dindependent with } \\
\text { mobilization (nallier } \\
\text { includes) }\end{array}$ \\
\hline $\begin{array}{l}\text { DDependent on balth care } \\
\text { providen for tuning and } \\
\text { repositioning }\end{array}$ & $\begin{array}{l}\text { Glyt requires asistance with } \\
\text { tuming and repositioning }\end{array}$ & DPt sole to reposition salf \\
\hline Digolation requining PPE & OReverelisolation & DNoisolation \\
\hline
\end{tabular}

DO NOT DUPLICATE WITHOUT PERIISSION
B-COMPLEXITY*

\begin{tabular}{|c|c|c|}
\hline $\begin{array}{l}\text { Lerel 1(at least2 of the criteria; } \\
\text { if only one criteria then ptis } \\
\text { lerel 2) }\end{array}$ & $\begin{array}{l}\text { Lerel 2 (atleast2 of the criteria } 0 R \\
\text { only one in level } 1 \text { \& one in level } 2 \text { ) }\end{array}$ & Letel 3 \\
\hline 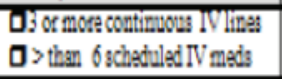 & Q2 to 6 sckediedIV madi & 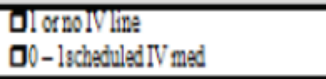 \\
\hline 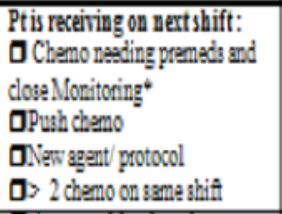 & 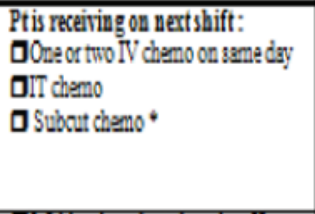 & $\begin{array}{l}\text { Ptis receiring on uertshift: } \\
\text { aNoIV chemo } \\
\text { aPO chemo }\end{array}$ \\
\hline 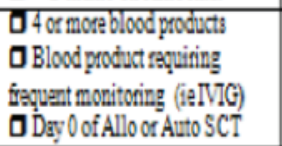 & $\begin{array}{l}\text { Q2-3bloodproducts based on Hg of } \\
\text { platelat levels }\end{array}$ & $\begin{array}{l}\text { DWo Blood products of } \\
1 \text { blood product }\end{array}$ \\
\hline 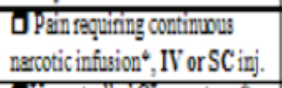 & $\begin{array}{l}\text { oControlled pein with schatuled and } \\
\text { / or brealthrough oral medications }\end{array}$ & dNopain \\
\hline $\begin{array}{l}\text { DUncontrolled G: oymptoms" } \\
\text { equiring sdditional interventions }\end{array}$ & $\begin{array}{l}\text { DCootrollad Gi symptoms" with } \\
\text { schatulad interventions }\end{array}$ & $\begin{array}{l}\text { DNo G symptoms" or no intervention } \\
\text { asdad }\end{array}$ \\
\hline 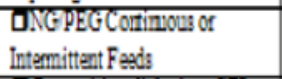 & QIPN & 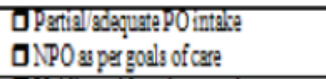 \\
\hline DPtrequiring dialyzis or CBI & $\begin{array}{l}\text { OHas achadiled bladder scanning } \\
\text { QIndwalling of intemitent cath }\end{array}$ & DViding without intervention \\
\hline $\begin{array}{l}\text { UStage } 3 \text { and } 4 \text { wounds } \\
\text { QNert Day shift : Pt requiring } \\
\text { extensive akin and wound cre* }\end{array}$ & 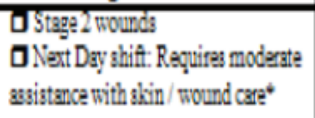 & $\begin{array}{l}\text { DStage I wound fequifing miminal } \\
\text { assistance or no wound }\end{array}$ \\
\hline 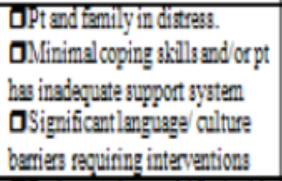 & 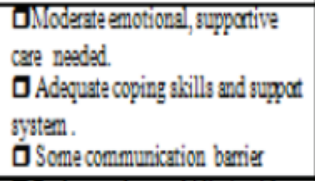 & $\begin{array}{l}\text { DPt and family not indistress. } \\
\text { QGood suppot system } \\
\text { QNo communication berrier }\end{array}$ \\
\hline 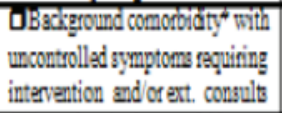 & $\begin{array}{l}\text { D Background comorbidity with } \\
\text { controlled symptoms and requiring } \\
\text { intervantions }\end{array}$ & $\begin{array}{l}\text { DNo comorbidity or comorbidity not } \\
\text { requiring interventions }\end{array}$ \\
\hline 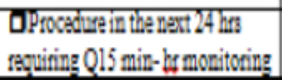 & 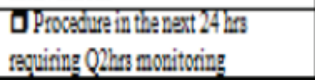 & 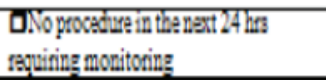 \\
\hline $\begin{array}{l}\text { DUPHQJERS } \\
\text { DCBGQD }\end{array}$ & $\begin{array}{l}\text { D BDblood wod } \\
\text { QCBGBD }\end{array}$ & DDEly bloctrod: \\
\hline
\end{tabular}

\section{C- PREDICTABLITY}

\begin{tabular}{|c|c|c|}
\hline Lerel l(one of the following) & Lerel 2( one of the following) & Lerel 3 \\
\hline 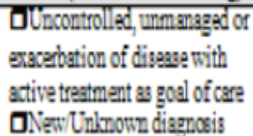 & $\begin{array}{l}\text { DPt improving on trestment } \\
\text { QManging pt symptoms and } \\
\text { response to trestment (dhemo or } \\
\text { transplent) }\end{array}$ & $\begin{array}{l}\text { DDisease rell-controlled or mangged } \\
\text { QPalliative: End stage congnunt with goal } \\
\text { of trastment }\end{array}$ \\
\hline DNo diachargeplaned & $\begin{array}{l}\text { Olo be dischaged within } \\
72 \mathrm{~kg}\end{array}$ & $\begin{array}{l}\text { DTo be diacherged within } \\
24 \mathrm{~km}\end{array}$ \\
\hline
\end{tabular}


the model to a hematology unit represents pioneering work and offers a tool and methodology that can be used in other patient populations. The limitations and challenges that we encountered can be ameliorated through various strategies that have been discussed. The flexible nature of the model is well suited to meeting the fluctuating acuity and needs of hematology/HSCT patients. The model enables healthcare administrators to make more informed, effective, real-time decisions about resource utilization and allocation in response to changes in patient acuity.

Finally, as CANO (2017) advocates: "the acuity level and complex needs of people with cancer require nurses to have a broad knowledge base." It is, therefore, important that both

\section{REFERENCES}

Benner, P. (1984). From novice to expert: Excellence and power in clinical nursing practice. Menlo Park: Addison-Wesley.

British Columbia Nurses Union. (2010). Provincial nursing workload project resource toolkit for teams: Nursing workload and staffing plan processes. Retrieved from https://www.bcnu.org/Safeworkplace/DefendProfessionalPractice/Documents/pnwp_ resource_toolkit.pdf

Canadian Association of Nurses in Oncology. (2017). Rationale for Standards of care. Retrieved from http://www.cano-acio.ca/page/ standards_of_care

Canadian Association of Nurses in Oncology. (2002). Practice standards and competencies. Retrieved from http://www.cano-acio.ca/conep.

Carter, K.F., \& Burnette, H.D. (2011). Creating patient-nurse synergy on a medical-surgical unit. Medsurg Nursing, 20, 249-254.

Curley, M.A. (Ed.). (2007). Synergy: The unique relationship between nurses and patients. Indianapolis: Sigma Theta Tau International.

Curley, M.A. (1998). Patient-nurse synergy: Optimizing patient's outcomes. American Journal of Critical Care, 7, 64-72.

Gralton, K.S. \& Brett, S.A. (2012). Integrating the synergy model for patient care at Children's Hospital in Wisconsin. Journal of Pediatric Nursing, 27, 7481. patients' needs and nurses' competency be measurable in order to provide the best match that will optimize the care provided. The developed hematology patient acuity tool and nurse competency tool will allow oncology units to provide a better fit between the needs of their patients and nursing competency providing the care.

\section{ACKNOWLEDGEMENTS}

We would like to thank our project team, the staff and physicians of the hematology/HSCT unit and the Juravinski Cancer Centre Foundation and F. Hoffmann-La Roche Ltd., who provided funding and support for this pilot project.

Hertel, R. (2012). Regulating patient staffing: A complex issue. MedSurg Matters, 21(1), 3-7.

Kaplow, R., \& Reed, K. (2008). The AACN synergy model for patient care: A nursing model as a force of magnetism. Nursing Economics, 26, 1725.

Kerfoot, K.M., Lavandero, R., Cox, M., Triola, N., Pacinin, C., \& Hanson, D.M. (2006). Conceptual models and the nursing organization. Implementing the AACN synergy model for patient care. Nurse Leader, 2026.

MacPhee, M., Wardrop, A., Campbell, C., \& Wejr, P. (2011). The synergy professional practice model and its patient characteristics tool: A staff empowerment strategy. Nursing Leadership, 24, 4255.

MacPhee, M.K., Jewell, K., Wardrop, A., Ahmed, A., \& Mildon, B. (2010). British Columbia's provincial nursing workload project: Evidence to empowerment. Canadian Journal of Nursing Leadership, 23, 5463.

Pope, B. (2002). The synergy matchup. Nursing Management, 33, 3841. 